\title{
Acquired hypophosphatemic osteomalacia is easily misdiagnosed or neglected by rheumatologists: A report of 9 cases
}

\author{
LING LI $^{1}$, SHU-XIA WANG ${ }^{2}$, HONG-MEI WU ${ }^{3}$, DONG-LAN LUO ${ }^{3}$, \\ GUANG-FU DONG ${ }^{1}$, YUAN FENG ${ }^{1}$ and XIAO ZHANG $^{1}$ \\ Departments of ${ }^{1}$ Rheumatology, ${ }^{2}$ Nuclear Medicine and ${ }^{3}$ Pathology, Guangdong General Hospital, \\ Guangdong Academy of Medical Sciences, Guangzhou, Guangdong 510080, P.R. China
}

Received August 2, 2016; Accepted May 11, 2017

DOI: $10.3892 /$ etm.2018.6106

\begin{abstract}
The aim of the present study was to assist rheumatologists in differentiating hypophosphatemic osteomalacia (HO) from mimic rheumatology diseases. Clinical data was obtained from 9 patients with acquired HO, initially misdiagnosed as mimic rheumatologic diseases. The data were retrospectively analyzed and a literature review was performed. The etiology of the cases was as follows: Adefovir dipivoxil-induced Fanconi syndrome was present in 6 of the cases, 2 were tumors and 1 case was chronic nephropathy. The chief complaint was thoracic or back pain and arthralgia, followed by progressive muscle weakness and dramatic movement limitation. All patients were transferred to 3-6 hospitals for extended periods due to misdiagnosis with conditions such as ankylosing spondylitis, chronic arthritis, lumbar disc disease, osteoporosis and somatoform disorder. Hypophosphatemia was observed in the patients and bone scans revealed diffusely decreased tracer uptake, with multiple hot spots of fractured sites and involved joints. Furthermore, patients' bone density was markedly low compared with the normal range for their age and sex. In the present study, 6 of the patients recovered when adefovir dipivoxil was stopped. In 1 case, hypophosphatemia was ameliorated following tumor resection. The remaining patients, 1 with sub-skull tumor and 1 with chronic kidney disease, had poor prognoses due to incurable diseases. In conclusion, diagnosing $\mathrm{HO}$ is challenging for rheumatologists and physicians. Basic examinations of electrolyte balance and bone mineral density should be performed, as should tumor screening and a careful collection of patient medical history and drugs in young patients with unexplained
\end{abstract}

Correspondence to: Professor Xiao Zhang, Department of Rheumatology, Guangdong General Hospital, Guangdong Academy of Medical Sciences, 106 Zhongshan 2nd Road, Guangzhou, Guangdong 510080, P.R. China

E-mail: 13922255387@163.com

Key words: osteomalacia, hypophosphatemia, ankylosing spondylitis, adefovir dipivoxil, tumor thoracic or back pain and muscle weakness. Removing any secondary etiology, such as drugs may dramatically improve the patients clinical manifestations and result in an improved prognosis.

\section{Introduction}

Hypophosphatemic osteomalacia (HO) is an uncommon metabolic disease characterized by low concentrations of serum phosphate levels, which leads to reduced mineralization of the bone matrix (1). It may affect individuals of all ages and either gender. Typically, HO is either inherited (2), a result of tumor-induced osteomalacia (TIO) (3), drug-induced (4) or a symptom of chronic kidney disease (5). Patients with inherited or TIO have been widely reported on by endocrinology or oncology specialists, however HO is often misdiagnosed in clinical practice as ankylosing spondylitis (AS), chronic arthritis, lumbar disc disease, osteoporosis and somatoform disorder, as it typically presents with the same signs and symptoms of these rheumatologic diseases, including bone pains, thoracic or back pain, muscle weakness, proximal myopathy and arthralgia (6). Diagnosis of HO remains a challenge to rheumatologists and physicians due to its low prevalence and nonspecific manifestations. Screening blood tests for electrolytes, particularly serum phosphate and bone mineral density (BMD) is basic clue for diagnosis. Screening for hidden tumors, which are classified as phosphaturic mesenchymal or phosphaturic mesenchymal tumor mixed connective tissue variants is important for patients with $\mathrm{HO}$ without an obvious etiology or history. The majority of the tumors are of bone or soft tissue origin and positron emission tomography (PET)/computed tomography (CT) scans may be used to identify them (3). The prognosis of the disease depends on the etiology. The treatment or removal of secondary etiologies, including drugs and tumors has been reported to be particularly effective at improving the condition. It is necessary to supply basic supplementation to all patients with sufficient oral phosphate, elemental calcium and active vitamin D (7). The present study reported 9 misdiagnosed cases of $\mathrm{HO}$ in order to improve the recognition of this disease amongst rheumatologists and physicians. Adefovir dipivoxil-induced Fanconi syndrome was present in 6 of the cases, 2 were caused by tumors and 1 case was due to chronic nephropathy. 


\section{Case report}

Patients. A total of 9 patients with terminal diagnoses of $\mathrm{HO}$ were diagnosed and treated in the Department of Rheumatology at Guangdong General Hospital (Guangzhou, China) between January 2011 to August 2015. All patients had clear etiologies and no family history of the disease. The length of disease history ranged from 10 months to 5 years, and the male-to-female ratio was 7:2. Patient ages ranged from 22 to 55 years (mean, 40.9 years). Patients with endocrine or metabolic diseases were excluded. All patients were negative for autoantibodies and human leukocyte antigen-B27.

Methods. The whole diagnosis and treatment information of the 9 cases were retrospectively analyzed, including etiology, patient complaints, clinical manifestations, physical examinations, laboratory and radiology examinations, bone mineral density examinations, and all treatments and prognoses. A literature review was also conducted.

Etiology. As demonstrated in Table I, all patients had acquired HO, and 6 patients with chronic hepatitis B had adefovir dipivoxil-induced Fanconi syndrome. The duration of drug treatment was 4-6 years (mean, 4.8 years) and the duration of symptoms was 2-4 years (mean, 3.5 years). A total of 2 cases presented with tumors (one giant cell tumor in the forearm tendon sheath and one sub-skull tumor). Furthermore, 1 case presented with chronic nephropathy with insufficient function and tubule acidosis.

Clinical manifestations. All cases developed gradually and presented with thoracic and back pain and arthralgia of the hips, feet or shoulders, which was accompanied by gradually aggravated muscle weakness and severe limitation of movement. In 1 case, foot numbness developed with muscle spasms, and 1 case presented with dramatically decreased height, weakness in chewing and worn teeth.

Course of treatment and misdiagnosis. Of the patients, 5 were misdiagnosed with AS, 3 of which accepted etanercept treatment. Furthermore, 2 cases had chronic arthritis, 3 had lumbar vertebral disc disease, 4 had primary osteoporosis and 1 had somatoform disorder (Table I). These patients were transferred between 3-6 hospitals and departments, including orthopedics, the Traditional Chinese Medicine Department, psychology, nephrology and rheumatology. This is a common practice in China, as due to the organization of the medical system the patients are able to freely select their hospital. The longest period of misdiagnosis was 5 years, with no effective treatment.

Laboratory examination. As demonstrated in Table II, basic laboratory examinations were conducted on all patients and the results were as follows: Serum phophatase (P), 0.37-0.72 mmol/1 (mean, $0.55 \mathrm{mmol} / \mathrm{l}$ ); serum $\mathrm{Ca}, 2.01-2.28 \mathrm{mmol} / 1$ (mean, $2.16 \mathrm{mmol} / \mathrm{l}$ ); parathyroid hormone, $17.8-108.7 \mathrm{pg} / \mathrm{ml}$ (mean, $43.1 \mathrm{pg} / \mathrm{ml}$; normal range, $15-65 \mathrm{pg} / \mathrm{ml}$ ); and alkaline phosphatase, 155-492 U/1 (mean, 273.6 U/1;. In 2 patients, an insufficiency of 25-OH vitamin D (VitD) was observed. Results of $24 \mathrm{~h}$ urine $\mathrm{P}$ were within
21.8-60.04 mmol (normal, 3-42 mmol/24-h urine) in 6 cases (mean, 43. mmol). Serum fibroblast growth factor-23 (FGF-23) levels were not monitored.

Fanconi syndrome-related examination. A total of 6 cases with hepatitis B had drug-induced Fanconi syndrome (7), induced by adefovir dipivoxil. Blood gas analyses revealed that blood pH was 7.24-7.45 (mean, 7.28; normal, 7.35-7.45), $\mathrm{Cl}^{-}$was $106.6-120.1 \mathrm{mmol} / \mathrm{l}$ (mean, $110.8 \mathrm{mmol} / \mathrm{l}$; normal, $95-105 \mathrm{mmol} / \mathrm{l})$, bases excess was -13.9 to $1.7 \mathrm{mmol} / \mathrm{l}$ (mean, - $4.9 \mathrm{mmol} / \mathrm{l}$; normal, -3-3) and $\mathrm{HCO}_{3}^{-}$was 12-21.1 mmol/1 (mean, $19.7 \mathrm{mmol} / \mathrm{l}$; normal, $22-27 \mathrm{mmol} / \mathrm{l}$. Urine $\mathrm{pH}$ was 7-9 (mean, 7.25; normal, 5-8), urine protein was $0.25-0.75 \mathrm{~g} / 1$ (normal, negative) and urine glucose was 3-56 mmol/l (normal, negative; Table II).

Bone scan. Bone scans revealed decreased methylene diphosphonate uptake in all bones, and multiple hot spots of fractured ribs and involved joints, consistent with metabolic bone disease (Fig. 1).

Bone densitometry. All patients were demonstrated to have markedly low bone densities, with a $\mathrm{Z}$ score of $<-2.5$ (normal, $>-1)$.

Imageology. X-ray and CT scans were performed and these revealed multiple fractures located in the ilium, pubis, lumbar and ribs in 5 cases. Magnetic resonance imaging of the head revealed a $25 \times 18 \mathrm{~mm}$ tumor under the skull plate and outside the brain in 1 patient (Fig. 2).

Biopsy. Two patients accepted kidney biopsies and the results revealed proximal renal tubule lesions associated with the Fanconi syndrome (Fig. 3) as confirmed by histopathology. The tumor identified in the left forearm tendon sheath of 1 patient was identified as a tenosynovial giant cell tumor (Fig. 4) as confirmed by histopatology.

Treatment and prognosis. All patients accepted basic supplementation with oral phosphate supplements (30 doses, 50 $\mathrm{mg} / \mathrm{kg}$ /day in divided doses), elemental calcium $1 \mathrm{~g} /$ day and active vitamin D supplements (calcitriol $0.5 \mu \mathrm{g} /$ day). The 6 patients with hepatitis B ceased treatment with adefovir dipivoxil and recovered within 6 months. In 1 patient, hypophosphatemia was completely eradicated 3 days following tumor resection (patient was discharged after 1 week and no further follow up was performed). The patient that presented with a sub-skull tumor refused surgery, and at the 6 month follow-up his height had decreased by $10 \mathrm{~cm}$ and he reported prominent pain across the whole body. The patient with chronic kidney disease and tubule acidosis had a poor prognosis at the 6-month follow-up due to insufficient kidney function.

\section{Discussion}

Hypophosphatemia is defined as a serum phosphate level of $<0.8 \mathrm{mmol} / 1(2.5 \mathrm{mg} / \mathrm{dl}) ;<0.32 \mathrm{mmol} / 1(1 \mathrm{mg} / \mathrm{dl})$ is regarded as severe (8). It is caused by decreased intake and absorption of, and the increased loss or transcellular shift of phosphorus (9). The most common causes of $\mathrm{HO}$ are inherited 
Table I. General characteristics of patients with hypophosphatemic osteomalacia enrolled in the present study.

\begin{tabular}{|c|c|c|c|c|c|c|c|}
\hline Case & Sex & $\begin{array}{l}\text { Age, } \\
\text { years }\end{array}$ & $\begin{array}{l}\text { Duration of } \\
\text { complaint }\end{array}$ & Etiology & Misdiagnosis & $\begin{array}{l}\text { Total drug } \\
\text { history, } \\
\text { years }\end{array}$ & $\begin{array}{c}\text { Drug exposure } \\
\text { to symptom, } \\
\text { years }\end{array}$ \\
\hline 1 & $\mathrm{~F}$ & 39 & 3 years & Tumor (giant cell tumor) & $\begin{array}{l}\text { Lumbar disc disease, } \\
\text { osteoporosis }\end{array}$ & - & - \\
\hline 2 & M & 47 & 5 years & Tumor (sub-skull) & AS, osteoporosis & - & - \\
\hline 3 & M & 43 & 2 years & $\begin{array}{l}\text { Drug-induced } \\
\text { Fanconi syndrome }\end{array}$ & $\begin{array}{l}\text { Lumbar disc disease, } \\
\text { somatoform disorder, AS }\end{array}$ & 6 & 4 \\
\hline 4 & M & 43 & 2 years & Drug-induced fanconi syndrome & Chronic arthritis & 4 & 2 \\
\hline 5 & M & 34 & 17 months & Chronic nephropathy with acidosis & AS $\quad-$ & - & \\
\hline 6 & M & 22 & 10 months & Drug-induced fanconi syndrome & AS, chronic arthritis & 4 & 3 \\
\hline 7 & M & 50 & 1 year & Drug-induced fanconi syndrome & Hematological disease & 6 & 5 \\
\hline 8 & $\mathrm{~F}$ & 35 & 2 years & Drug-induced fanconi syndrome & AS, osteoporosis & 4 & 2 \\
\hline 9 & M & 55 & 1 year & Drug-induced fanconi syndrome & $\begin{array}{l}\text { Lumbar disc disease, } \\
\text { osteoporosis }\end{array}$ & 5 & 4 \\
\hline
\end{tabular}

F, female; M, male; AS, ankylosing spondylitis.

Table II. Biochemical test results for patients with hypophosphatemic osteomalacia enrolled in the present study.

Biochemical parameter

Serum P, Serum Ca, PTH, ALP, $\mathrm{Cl}^{-}$, Plasma Plasma BE, Serum $\mathrm{HCO}_{3}^{-}, 24 \mathrm{~h} \mathrm{U} \mathrm{P,} \mathrm{U} \mathrm{glucose,} \mathrm{U} \mathrm{protein,}$

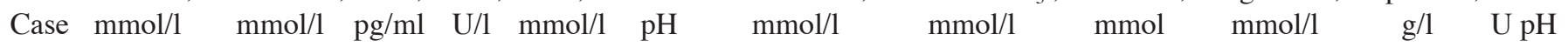

\begin{tabular}{rrrrrrrrccccccc}
\hline 1 & 0.40 & 2.18 & 95.0 & 155 & - & - & - & - & 60.0 & 56 & - & - \\
2 & 0.40 & 2.28 & 108.7 & 230 & 106.6 & 7.45 & 1.7 & - & 24.7 & - & - \\
3 & 0.72 & 2.01 & 19.2 & 271 & 110.8 & 7.30 & -4.3 & 19.7 & 23.3 & 3 & 0.75 & 8.0 \\
4 & 0.54 & 2.05 & 21.6 & 343 & 108.6 & - & - & - & - & - & - \\
5 & 0.57 & 2.13 & 17.8 & 185 & 120.1 & 7.24 & -13.9 & 12.0 & - & - & 0.25 & 9.0 \\
6 & 0.37 & 2.14 & 50.9 & 492 & 113.6 & 7.31 & -9.1 & 17.1 & - & 56 & 0.75 & 7.0 \\
7 & 0.65 & 2.23 & 28.8 & 352 & 109.2 & 7.26 & -3.2 & 21.1 & 22.5 & 3 & 0.25 & 7.0 \\
8 & 0.60 & 2.20 & 21.4 & 259 & 112.3 & 7.30 & -4.2 & 20.5 & 24.4 & 5 & 0.75 & 7.0
\end{tabular}

P, phosphate; PTH, parathyroid hormone; ALP, alkaline phosphatase; BE, bases excess; U, urine.

or tumor-induced(TIO), and have been widely studied by endocrinology or oncology specialists (2). Reports from rheumatologists of clinical musculoskeletal manifestations of $\mathrm{HO}$ are rare, with the exception of a report by Reginato et al (10). The authors of the present study reported a case of adefovir dipivoxil-induced Fanconi syndrome and HO in 2011 (7). In our previous report, the literature was reviewed and it was reported that $<10$ similar cases of this disease had been reported in clinical practice (7). The cases presented with clinical manifestations that mimicked primary musculoskeletal disease, and the course of treatment was typically difficult, which is indicative of the lack of recognition of $\mathrm{HO}$ by physicians.

The renal tubule regulates the excretion and absorption of calcium and phosphorus, which in turn affects bone tissues (8). In clinical practice, $20-25 \%$ of males and $>5 \%$ of females with osteoporosis exhibit renal tubule disorders including phosphate wasting, hypercalciuria and tubular acidosis (11).

Adefovir dipivoxil is commonly used for the treatment of chronic hepatitis B (12). Its renal toxicity is dose- and time-related, and often occurs in patients with a daily dose of $>30 \mathrm{mg}$ and those with impaired renal function (13). The mechanism by which adefovir dipivoxil causes kidney damage is that its product is mainly excreted by the kidneys and influences the reabsorption of renal tubule cells (13). Hyperphosphaturia is typically accompanied by hypophosphatemia (13).

The 6 patients with hepatitis $\mathrm{B}$ in the present study were treated with normal doses (10 $\mathrm{mg}$ /day) of adefovir dipivoxil for 2-4 years. This indicates that clinical attention should be given to adefovir dipivoxil-induced kidney damage in patients with a drug exposure $>2-3$ years (14), even if the drug dosage was 


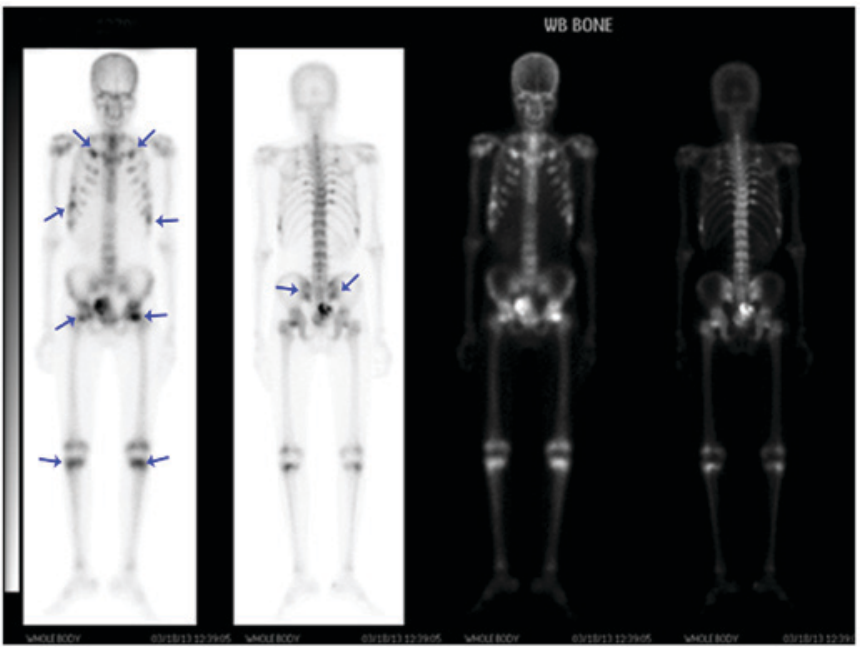

Figure 1. Decreased methylene diphosphonate uptake in all bones, and multiple hot spots (blue arrows) of fractured ribs and involved joints.

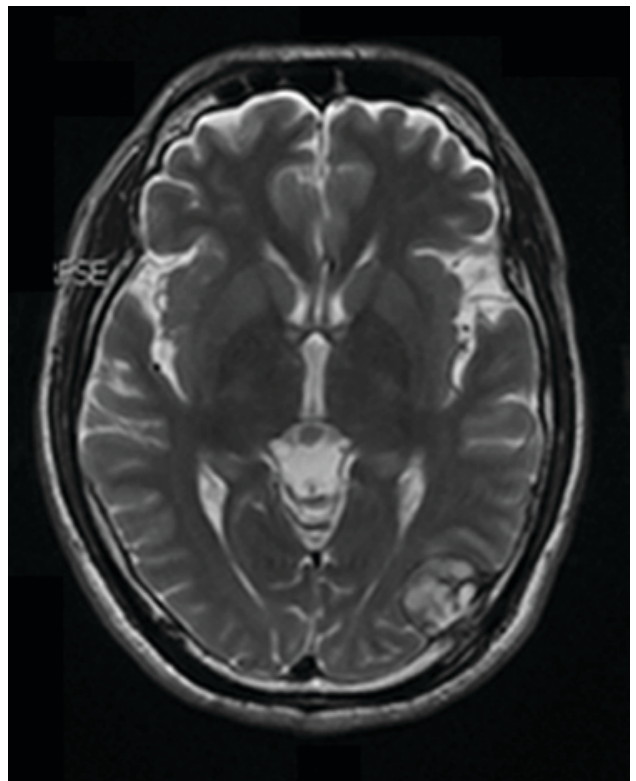

Figure 2. Magnetic resonance imaging of the head in 1 case revealed a tumor under the skull plate and outside the brain with a size of $25 \times 18 \mathrm{~mm}$.

within the normal range. TIO typically occurs in the bone and soft tissues of the upper or lower limbs and skull, and rarely in the trunk and axial bone (15). A study by Jiang et al (3) reported that the majority of tumors $(85 \%)$ in TIO were classified as phosphaturic mesenchymal tumors or phosphaturic mesenchymal tumor mixed connective tissue variants. These tumors are of bone (40\%) or soft tissue (55\%) origin, and $42 \%$ are located in the lower extremities (3). TIO is a common cause of adult-onset hypophosphatemia in China (15). It was reported that $68 \mathrm{Ga}$ DOTA-octreotate PET/CT performed better than ${ }^{18} \mathrm{~F}$-fluorodeoxyglucose PET/CT, and is useful for the detection of tumors that cause oncogenic osteomalacia (15). In the majority of cases, successful removal of tumors leads to recovery; however, long term follow-up should be performed in case of recurrence (16).

Of the phosphate excreted by the kidney, $\sim 80 \%$ is reabsorbed by the proximal renal tubule through the natrium-potassium

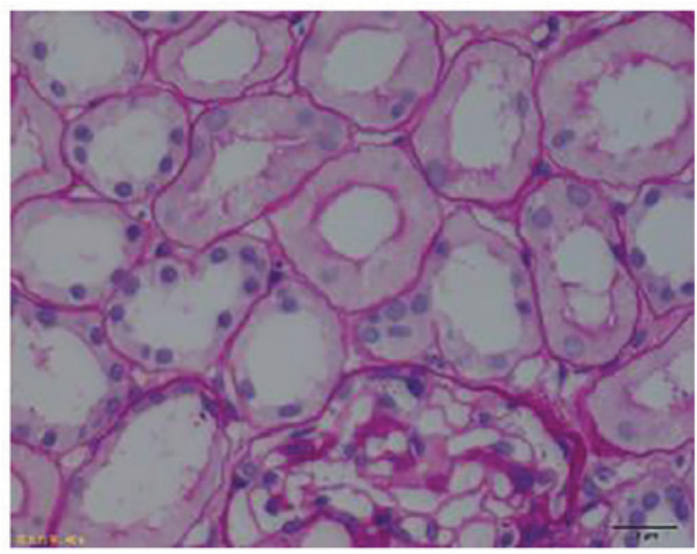

Figure 3. Two kidney biopsies revealed proximal renal tubule lesions associated with Fanconi syndrome (Periodic acid-Schiff staining; magnification, $\mathrm{x} 400)$.

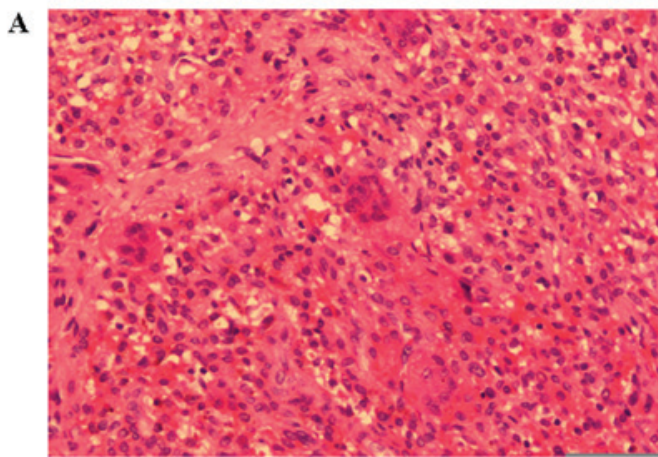

B

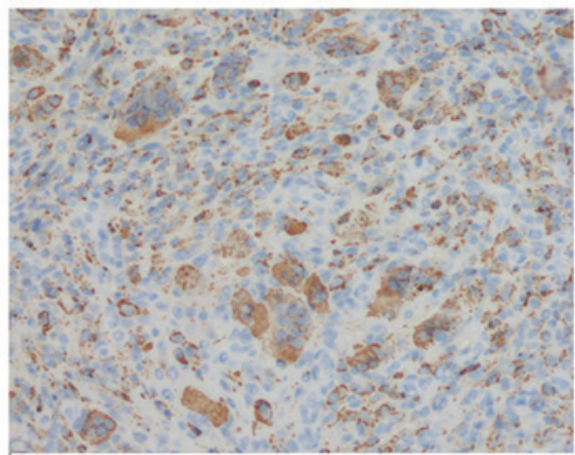

Figure 4. Histopathology of the tumor in the tendon sheath of the left forearm. Tenosynovial giant cell tumor, localized type. (A) A typical mixture of small histiocytoid cells and osteoclastic giant cells (hematoxylin \& eosin; magnification, x200). (B) The smaller histiocyte-like cells and multinucleate giant cells are CD68 positive (immunohistochemical staining; magnification $\mathrm{x} 200)$.

co-transfer protein IIa (NaP IIa) (17). These TIO associated tumors excrete FGF-23, and suppress the recruitment, and expression of NaP IIa and the reabsorption of phosphorus (17), increasing phosphorus drainage. Furthermore, FGF-23 influences the activity of 1- $\alpha$ hydroxylase in kidneys to decrease the formation of $1.25(\mathrm{OH})_{2} \mathrm{D} 3$ and the intake of phosphate in the intestine (18). Bone mineralization is hindered by hypophosphatemia and the insufficiency of serum $1.25(\mathrm{OH})_{2} \mathrm{D} 3(9)$.

Fracture lines in osteomalacia are very common (19), and may consist of pseudo fractures, true fractures or insufficiency fractures. Pseudo fractures are characteristic of HO (20). 
The diagnostic criteria of a pseudo fracture are as follows: i) Imaging manifestations of osteomalacia; and ii) the predilection site of the pseudo fracture is the pubic branch, medial of the femur neck, medial of the femur shaft, the femur lesser trochanter, lateral of the scapula, rib, or proximal and posterior of the ulna. Thin slice CT scans and three-dimensional reconstruction techniques are able to accurately display the pseudo fracture line (20). The pseudo fracture may be used as an imaging index to evaluate patient condition (20).

The differential diagnoses of HO include primary osteoporosis, multiple myeloma and hyperparathyroidism with consensus (21). However, it must be noted that the clinical presentation of HO typically mimics rheumatologic diseases, in particular AS, chronic arthritis or myopathy, and primary hospitals often misdiagnose $\mathrm{HO}$ due to insufficient examination. Treatment methods and prognoses depend on the etiology of the disease, and the most effective treatments target the underlying cause of HO (22). Clinically, physicians should perform basic electrolyte examinations when presented with young patients with unexplained back pain and muscle weakness. Screening tumors in soft tissues and bones is also important to achieve early diagnosis, effective treatment and a positive long-term prognosis (23).

\section{Competing interests}

The authors declare that they have no competing interests.

\section{References}

1. Carpenter TO: The expanding family of hypophosphatemic syndromes. J Bone Miner Metab 30: 1-9, 2012.

2. Che H, Roux C, Etcheto A, Rothenbuhler A, Kamenicky P, Linglart A and Briot K: Impaired quality of life in adults with $\mathrm{X}$-linked hypophosphatemia and skeletal symptoms. Eur J Endocrinol 174: 325-333, 2016.

3. Jiang Y, Xia WB, Xing XP, Silva BC, Li M, Wang O, Zhang HB, Li F, Jing HL, Zhong DR, et al: Tumor-induced osteomalacia: An important cause of adult-onset hypophosphatemic osteomalacia in China: Report of 39 cases and review of the literature. J Bone Miner Res 27: 1967-1975, 2012.

4. Wang XB, Zhu XC, Huang XY, Ye WJ and Wang LX: Fanconi syndrome due to prolonged use of low-dose adefovir. J Res Med Sci 20: 416-419, 2015.

5. Kazama JJ, Matsuo K, Iwasaki Y and Fukagawa M: Chronic kidney disease and bone metabolism. J Bone Miner Metab 33: 245-52, 2015.

6. Yuan T, Shi L, Xia WB, Xing XP and Meng XW: Fanconi syndrome misdiagnosed as ankylosing spondylitis for several years. Chin J Osteoporosis and Bone Mineral Res 4: 281-284, 2012.
7. Li L, Dong GF, Zhang X and Xie YS: Adefovir dipivoxil-induced Fanconi syndrome and hypophosphatemic osteomalacia associated with muscular weakness in a patient with chronic hepatitis B. Nan Fang Yi Ke Da Xue Xue Bao 31: 1956-1957, 2011.

8. Berkelhannner C and Bear RA: A clinical approach to common electrolyte problems: 3. Hypophosphatemia. Can Med Assoc J 130: 17-23, 1994.

9. Munoz J, Michel Ortega R, Celzo F and Donthireddy V: Tumour-induced osteomalacia. BMJ Case Rep 25: bcr.0320125975, 2012.

10. Reginato AJ, Falasca GF, Pappu R, McKnight B and Agha A: Musculoskeletal manifestations of osteomalacia: Report of 26 cases and literature review. Semin Arthritis Rheum 28: 287-304, 1999.

11. Laroche M, Cesini J and Tack I: Osteoporosis and renal tubular Dysfunction. Joint Bone Spine 79: S96-S98, 2012.

12. Gara N, Zhao X, Collins MT, Chong WH, Kleiner DE, Jake Liang T, Ghany MG and Hoofnagle JH: Renal tubular dysfunction during long-term adefovir or tenofovir therapy in chronic hepatitis B. Aliment Pharmacol Ther 35: 1317-1325, 2012.

13. Izzedine H, Hulot JS, Launay-Vacher V, Marcellini $P$, Hadziyannis SJ, Currie G, Brosgart CL, Westland C, Arterbrun S, Deray G, et al: Renal safety of asdefovir dipivoxil in patients with chronic hepatitis B: Two double-blind, randomized, placebo-controlled studies. Kidney Int 66: 1153-1158, 2004

14. Law ST, Li KK and Ho YY. Nephrotoxicity, including acquired fanconi's syndrome, caused by adefovir dipivoxil is there a safe dose? J Clin Pharm Ther 37: 128-131, 2012.

15. Agrawal K, Bhadada S, Mittal BR, Shukla J, Sood A, Bhattacharya A and Bhansali A: Comparison of 18F-FDG and $68 \mathrm{Ga}$ DOTATATE PET/CT in localization of tumor causing oncogenic osteomalacia. Clin Nucl Med 40: e6-e10, 2015.

16. Ray S, Chakraborty PP, Biswas K, Beatrice AM, Ghosh S, Mukhopadhyay S and Chowdhury S: Oncogenic osteomalacia caused by occult nasal mesenchymal tumor: A monster in the cave. Oxf Med Case Reports. 265-268, 2015.

17. Jonsson KB, Zahradnik R, Larsson T, White KE, Sugimoto T, Imanishi Y, Yamamoto T, Hampson G, Koshiyama H, Ljunggren $\mathrm{O}$, et al: Fibroblast growth factor 23 in oncogenic osteomalacia and X-linked hypophosphatemia. N Engl J Med 348: 1656-1663, 2003.

18. Gattineni J and Baum M: Regulation of phosphate transport by fibroblast growth factor 23 (FGF23): Implications for disorders of phosphate metabolism. Pediatr Nephrol 25: 591-601, 2010.

19. Lee YS, Kim BK, Lee HJ and Dan J: Pathologic femoral neck fracture due to fanconi syndrome induced by adefovir dipivoxil therapy for hepatitis B. Clin Orthop Surg 8: 232-236, 2016.

20. Lee C, Lashari S: Pseudofracture of the neck of femur secondary to osteomalacia. J Bone Joint Surg Br 89: 956-958, 2007.

21. Reilly BM, Hart PD, Mascarell S and Chatrath H: Clinical problem-solving. A question well put. N Engl J Med 360: 1446-1451, 2009.

22. Jan de Beur SM; Tumor-induced osteomalacia. JAMA 294: 1260-1267, 2005

23. Yu WJ, He JW, Fu WZ, Wang C and Zhang ZL: Reports of 17 Chinese patients with tumor-induced osteomalacia. J Bone Miner Metab 35: 298-307, 2017. 